Article

\title{
A Didactic Procedure to Solve the Equation of Steady-Static Response in Suspended Cables
}

\author{
José Agüero-Rubio ${ }^{1}\left(\mathbb{D}\right.$, Javier López-Martínez ${ }^{2}$, ${ }^{2}$ Marta Gómez-Galán ${ }^{2}$ and \\ Ángel-Jesús Callejón-Ferre $2, *$ (1) \\ 1 Department of Electricity, IES Alhamilla of Almería, 04005 Almería, Spain; ele10jose@iesalhamilla.com \\ 2 Department of Engineering, University of Almería, Research Center CIAIMBITAL (CeiA3), Ctra. Sacramento, \\ s/n, La Cañada, 04120 Almería, Spain; javier.lopez@ual.es (J.L.-M.); mgg492@ual.es (M.G.-G.) \\ * Correspondence: acallejo@ual.es
}

Received: 8 August 2020; Accepted: 27 August 2020; Published: 1 September 2020

check for updates

\begin{abstract}
Students in the electrical branch of the short-cycle tertiary education program acquire developmental and design skills for low voltage transmission power lines. Aerial power line design requires mathematical tools not covered well enough in the curricula. Designing suspension cables requires the use of a Taylor series and integral calculation to obtain the parabola's arc length. Moreover, it requires iterative procedures, such as the Newton-Raphson method, to solve the third-order equation of the steady-static response. The aim of this work is to solve the steady-static response equation for suspended cables using simple calculation tools. For this purpose, the influence of the horizontal component of the cable tension on its curvature was decoupled from the cable's self-weight, which was responsible for the tension's vertical component. To this end, we analyzed the laying and operation of the suspended cables by defining three phases (i.e., stressing, lifting, and operation). The phenomena that occurred in each phase were analyzed, as was their manifestation in the cable model. Herein, we developed and validated the solution of the steady-static response equation in suspended cables using simple equations supported with intuitive graphics. The best results of the proposed calculation procedure were obtained in conditions of large temperature variations.
\end{abstract}

Keywords: power transmission lines; suspended cables; reduced-order models; problem-based learning; mathematical modeling; high-temperature and low-sag conductors (HTLS conductors)

\section{Introduction}

Programs like vocational education and training studies for electrical and automatic systems (Spanish Royal Decree (RD) 1127/2010 [1]) and short-cycle tertiary education (classified at an international standard classification of education (ISCED) level 5 [2]) are designed to provide participants with professional knowledge, skills, and competencies. Academic tertiary education programs below the level of a bachelor's program or equivalent are also classified as ISCED level 5.

The mathematical competencies with which students enter these studies do not include differential or integral calculus. According to RD 1127/2010 [1], electrical and mechanical calculations are required for low voltage power transmission lines. The mathematical model that describes the behavior of the cable is based on the catenary curve and, in most cases, the parabola is used as an approximation, as it is easier to apply [3]. The use of a Taylor series is required to approximate both the profile and length of the cable $[4,5]$. The arc length of the parabola is essential for solving the steady-static response equation of the cable [6,7]. It is a polynomial equation that can be solved with a simple code [7]. Both a Taylor series and iterative resolution algorithms take the student away from real physical phenomena. According to Huilier [8], difficulties in mathematics are the main obstacle for young students to get interested in science and technology disciplines. When studying the subject of suspended cables in the 
final years of secondary education, students ask themselves questions such as: What length of cable is necessary to join two points? Since students do not have integral calculation tools, they often cannot answer this question and resort to formulas that need to be memorized.

According to Moreno-Clemente [9], computers are a valuable tool for calculating power transmission lines. It is also important for students to analyze the physical implications of each approximation made in the mathematical model. It is important that students learn how to do science [10]. When considering problem-solving activities applied to the cables, there is an initial part that students can do on their own (i.e., puzzle activities [11]) and a final part in which they use computer applications as the only tool to obtain a quick solution to the static response equation.

In this paper, we propose a procedure that in only two steps provides an approximate solution to the real solution. In this way, the student is encouraged to use mathematical models of reduced order to solve the whole problem. The problem has become a puzzle situation [11] by having a fixed (approximate) solution. Proposing appropriate strategies for problem-solving is important to correctly achieve conceptual and procedural competencies [12].

The student uses reduced-order models to compare the results obtained by the proposed procedure and those provided by computer applications when using higher-order models. The student is allowed to build his own knowledge and draw his own conclusions through the use of different mathematical models for the same physical system. It is important to highlight student motivations for using accurate and simplified mathematical models [13,14], as well as graphic and intuitive tools [15].

Regarding the detailed models of suspended cables, Irvine [16] carried out a complete study of static equations for state of the suspended cables. Changes in the static state of suspended cables are due to temperature variations [17,18], ice loads [19,20], moving mass [21-23], vibrations [24-27], or intentional power overloads that raise cable temperatures [28]. Although most of the works start from an initial static curved state [16-28], Yang [29] considered the initial state without mechanical tension (stress) and with the cable in a horizontal position. Luongo and Zulli [30] described the first step in solving the static response equation in cables under vertical loads.

In this work, we start from an initial state of the cable without curvature and support the cable on a horizontal surface. The aim is to decouple the influence that the horizontal component of the cable tension had on the cable curvature and the cable's own weight, which is responsible for vertical component tension. To achieve this, the laying and operation of the suspended cables were analyzed in detail by defining three phases. Phase I is stressing, during which the external horizontal force was applied to the cable. Phase II is lifting, during which the vertical external force was applied and the cable acquired curvature, defining its profile. This phase was studied in detail and the energy relationships were analyzed. Finally, phase III is operation, in which we proposed a procedure to solve the steady-static response equation using simple equations. This last phase was traditionally studied.

The aim of this work was to provide a calculation procedure to solve the static response equation for suspended cables using simple arithmetic operations and intuitive graphics that allow locating the main physical magnitudes.

This paper is organized as follows. Section 2 describes the mathematical models of static equilibrium of suspended cables. Section 3 describes the three phases for the laying and operation of the suspended cables and the procedure to obtain an approximation of the equation of static state change for the cable. At the end of Section 3, we show several examples solved by vocational education and training students of the electricality branch (secondary school Alhamilla (Almería), Spain).

\section{Materials and Methods}

This section describes the mathematical models of the static equilibrium for suspended cables [16]. The loads of the displaced state [16] were modified by introducing a load per unit length in the displaced state, $m_{2}$, which was different from the load per unit length of the initial state, $m_{1}$. Moreover, given the importance of suspended cables applied to low voltage overhead lines, the temperature 
variation in both states, $t_{2}$ and $t_{1}$, respectively, was considered. Finally, we obtained the static state change equation for cables suspended between two fixed supports $A$ and $B$ (see Figure 1).

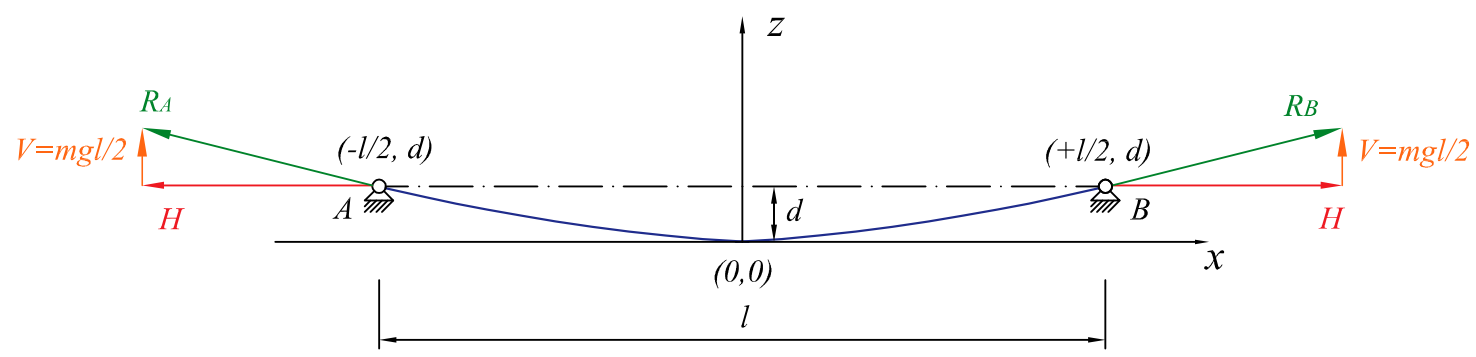

Figure 1. Cable profile for one static equilibrium state.

\subsection{Initial Static State: Subscript 1}

The static equilibrium of the cable was previously obtained [16].

$$
\frac{d}{d s_{1}}\left(T_{1} \frac{d x}{d s_{1}}\right)=0, \quad \frac{d}{d s_{1}}\left(T_{1} \frac{d z}{d s_{1}}\right)=m_{1} g
$$

Herein, $d s_{1}$ is the initial length of a differential element of the cable, $T_{1}$ is the tension inside the cable and $m_{1} g$ is the self-weight of the cable per unit length in the initial static state and $x-z$ are the Cartesian coordinates. We use the following restrictions:

$$
\left(\frac{d x}{d s_{1}}\right)^{2}+\left(\frac{d z}{d s_{1}}\right)^{2}=1 \rightarrow \frac{d s_{1}}{d x}=\sqrt{1+\left(\frac{d z}{d x}\right)^{2}}
$$

Further, we solve

$$
\left(T_{1} \frac{d x}{d s_{1}}\right)=H_{1}, \quad\left(H_{1} \frac{d^{2} z}{d x^{2}}\right)=m_{1} g \sqrt{1+\left(\frac{d z}{d x}\right)^{2}}
$$

where $H_{1}$ is the horizontal component of the applied external force.

The cable profile is a catenary (hyperbolic cosine function) and can be approximated by a flat parabola, as shown in Figure 1. For the small sag, the static equilibrium equation simplifies into [17]

$$
\frac{d}{l}<\frac{1}{8} \Rightarrow\left(\frac{d z}{d x}\right)^{2}<<1 \rightarrow H_{1} \frac{d^{2} z}{d^{2} x}=m_{1} g
$$

where $l$ is its span.

The boundary conditions are

$$
z\left(-\frac{l}{2}\right)=z\left(+\frac{l}{2}\right)=d, \quad z(0)=0 .
$$

The solution for the cable profile is then

$$
z(x)=\frac{m_{1} g x^{2}}{2 H_{1}} .
$$

The sag is

$$
d=\frac{m_{1} g l^{2}}{8 H_{1}}
$$

Figure 1 shows the cable suspended between two fixed points: $A$ and $B$ and Cartesian coordinates $((-l / 2, d)$ and $(+l / 2, d)$, respectively). The vertical external force on the support is $V$ and $H$ is the 
horizontal external force, which coincides with the constant horizontal component of cable tension. One must have $H>V$ (for $d / l$ to be less than 1/8). The cable length, $L$, can be approximated by a first-order Taylor:

$$
L=\int_{0}^{l} \sqrt{1+\left(\frac{d z}{d x}\right)^{2}} d x, \quad L=l\left(1+\frac{m_{1}^{2} g^{2} l^{2}}{24 H_{1}^{2}}\right)
$$

This is mechanical, i.e., the length of the profile [16,17].

\subsection{Stressed Static State: Subscript 2}

Figure 2 shows the geometry of when the cable is displaced from its original equilibrium profile [16], where $d s_{1}$ is the original length of the element, $d s_{2}$ is its new length, and $u$ and $w$ are the longitudinal and vertical components of the displacement, respectively.

$$
\begin{gathered}
d s_{1}^{2}=d x^{2}+d z^{2} \\
d s_{2}^{2}=(d x+d u)^{2}+(d z+d w)^{2}
\end{gathered}
$$

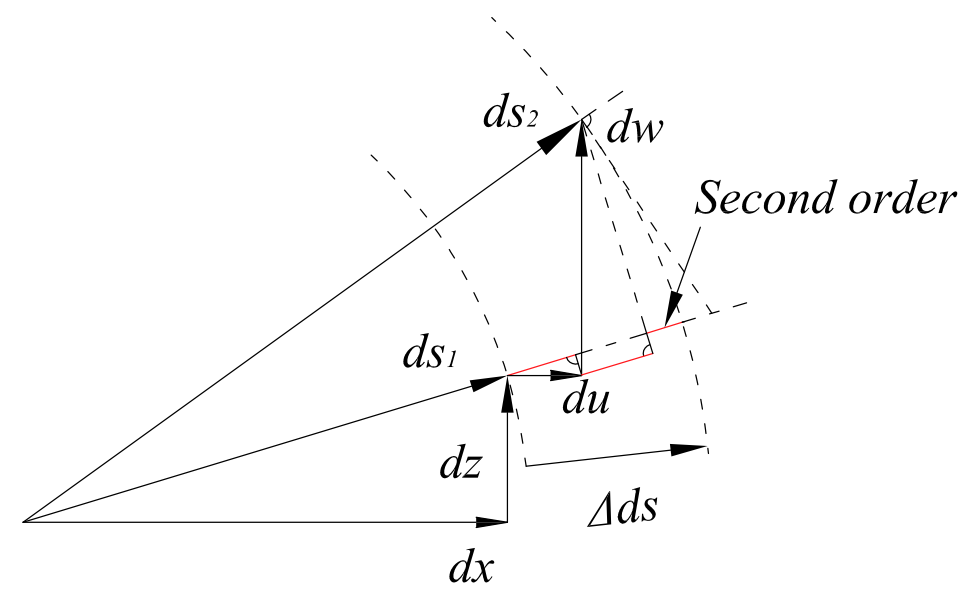

Figure 2. Displacement of an element of the cable. (Adapted from [16]).

The state of equilibrium then follows Equation (10) [17], although in the present work the weight of the cable in the displaced state is $m_{2} g$.

$$
\frac{d}{d s_{2}}\left[T_{2}\left(\frac{d x+d u}{d s_{2}}\right)\right]=0, \quad \frac{d}{d s_{2}}\left[T_{2}\left(\frac{d z+d w}{d s_{2}}\right)\right]=m_{2} g
$$

By using the restrictions, we find

$$
\left(\frac{d x+d u}{d s_{2}}\right)^{2}+\left(\frac{d z+d w}{d s_{2}}\right)^{2}=1 \rightarrow \frac{d s_{2}}{d x}=\sqrt{1+\left(\frac{d z+d w}{d x}\right)^{2}}
$$

Moreover, we solve

$$
T_{2}\left(\frac{d x+d u}{d s_{2}}\right)=H_{2}, \quad H_{2} \frac{d^{2}(z+w)}{d x^{2}}=m_{2} g \sqrt{1+\left(\frac{d z+d w}{d x}\right)^{2}} .
$$


Herein, $T_{2}$ is the tension inside the cable in the displaced state. For small sag, the static equilibrium equation simplifies into [17]

$$
\frac{d}{l}<\frac{1}{8} \Rightarrow\left(\frac{d z+d w}{d x}\right)^{2}<<1 \rightarrow H_{2} \frac{d^{2}(z+w)}{d x^{2}}=m_{2} g .
$$

Using (13), (12) becomes

$$
T_{2}\left(\frac{d x+d u}{d s_{2}}\right)=H_{2}, \quad H_{2} \frac{d^{2}(z+w)}{d x^{2}}=m_{2} g .
$$

Equation (14) then becomes

$$
T_{2}(d x+d u)=H_{2} d s_{2}=H_{2}\left(d s_{1}+\Delta d s\right)
$$

where $\Delta d s$ is the module of the length variation between the length of the displaced state $s_{2}$, and the length of the initial state $s_{1}$ (see Figure 2). Substituting (3) into (15),

$$
T_{1} d x=H_{1} d s_{1} \rightarrow\left(T_{2}-T_{1}\right) d x+T_{2} d u=\left(H_{2}-H_{1}\right) d s_{1}+H_{2} \Delta d s .
$$

When the cable is curved and suspended between two fixed points [16] it is assumed that: $\Delta d s<<d x$ y $d u<<d x$. Then, the following value results for $T^{\prime}$ :

$$
\left(T_{2}-T_{1}\right) \approx\left(H_{2}-H_{1}\right) \frac{d s}{d x} \rightarrow T^{\prime} \approx h \frac{d s}{d x}
$$

where $T^{\prime}=\left(T_{2}-T_{1}\right)$ and $h=\left(H_{2}-H_{1}\right)$, according to a prior notation [16].

With respect to Equation (14), the second becomes

$$
H_{2} \frac{d^{2} z}{d x^{2}}+H_{2} \frac{d^{2} w}{d x^{2}}=m_{2} g .
$$

By substituting (4) into (18):

$$
\frac{d^{2} w}{d x^{2}}=\frac{m_{2} g}{H_{2}}-\frac{m_{1} g}{H_{1}}
$$

Further, integrating in (19) results in

$$
w(x)=\left(\frac{m_{2} g}{H_{2}}-\frac{m_{1} g}{H_{1}}\right) \frac{x^{2}}{2} .
$$

On the other hand, the variation of cable length exclusively attends to geometric considerations (see Figure 2) and corrects the second order of small quantities [16,25].

$$
\begin{aligned}
d s_{2}-d s_{1} & =\frac{d x}{d s_{1}} d u+\frac{d z}{d s_{1}} d w+\left(\frac{1}{2} \frac{d w}{d s_{1}}\right) d w \\
\frac{d s_{2}-d s_{1}}{d s_{1}} & =\frac{d x}{d s_{1}} \frac{d u}{d s_{1}}+\frac{d z}{d s_{1}} \frac{d w}{d s_{1}}+\frac{1}{2}\left(\frac{d w}{d s_{1}}\right)^{2}
\end{aligned}
$$

When the cable is fixed between two supports, the change in cable length is due to changes in its internal tension, according to Hooke's law [31] and variations in cable temperature [32].

$$
\frac{T^{\prime}}{E A}+\alpha \Delta t=\frac{d s_{2}-d s_{1}}{d s_{1}}=\frac{\Delta d s}{d s_{1}}
$$

Here, $E, A$, and $T^{\prime}$ denote the Young modulus, the cross-section area, and the additional tension exerted on the element, respectively. $\alpha$ is the thermal expansion coefficient and $\Delta t$ is the temperature 
change of the cable. By putting Equation (21) into (22), the cable equation for an element $d s_{1}$ is as follows:

$$
\frac{T^{\prime}}{E A}+\alpha \Delta t=\frac{d x}{d s_{1}} \frac{d u}{d s_{1}}+\frac{d z}{d s_{1}} \frac{d w}{d s_{1}}+\frac{1}{2}\left(\frac{d w}{d s_{1}}\right)^{2} .
$$

Substituting (17) into (23) allows for the following:

$$
\left(\frac{h}{E A} \frac{d s_{1}}{d x}+\alpha \Delta t\right)\left(\frac{d s_{1}}{d x}\right)^{2}=\frac{d u}{d x}+\frac{d z}{d x} \frac{d w}{d x}+\frac{1}{2}\left(\frac{d w}{d x}\right)^{2} .
$$

If the $A$ and $B$ supports are fixed, there is no horizontal movement between them. Therefore the integral of the first summand in the right hand side of (24) is zero.

$$
\int_{-\frac{1}{2}}^{+\frac{1}{2}} d u=0
$$

The integral of the second summand on the right side in (24) is as follows:

$$
\int_{-\frac{1}{2}}^{+\frac{1}{2}} \frac{d z}{d x} \frac{d w}{d x} d x=\int_{-\frac{1}{2}}^{+\frac{1}{2}} \frac{m_{1} g x}{H_{1}}\left(\frac{m_{2} g}{H_{2}}-\frac{m_{1} g}{H_{1}}\right) x d x=2 \frac{m_{1} g x}{H_{1}}\left(\frac{m_{2} g}{H_{2}}-\frac{m_{1} g}{H_{1}}\right) \frac{l^{3}}{24}
$$

The integral of the third summand of the right side in (24) is as follows:

$$
\int_{-\frac{1}{2}}^{+\frac{1}{2}} \frac{1}{2}\left(\frac{d w}{d x}\right)^{2} d x=\int_{-\frac{1}{2}}^{+\frac{1}{2}}\left(\frac{m_{2} g}{H_{2}}-\frac{m_{1} g}{H_{1}}\right)^{2} \frac{x}{2} d x=\left(\frac{m_{2} g}{H_{2}}-\frac{m_{1} g}{H_{1}}\right)^{2} \frac{l^{3}}{24}
$$

Assuming $d s_{1} \approx d x$, integrating (24) and substituting (25)-(27) obtains the following:

$$
\frac{\left(H_{2}-H_{1}\right)}{E A} l+\alpha\left(t_{2}-t_{1}\right) l=\frac{m_{2}^{2} g^{2} l^{3}}{24 H_{2}^{2}}-\frac{m_{1}^{2} g^{2} l^{3}}{24 H_{1}^{2}} .
$$

This is a third-order equation with $\mathrm{H}_{2}$ as the unknown. It is the equation of steady-static response that students need to solve. It can be solved using Cardano's formulae, Ruffini's rule or some other procedure for solving cubic equations.

\section{Results}

As a starting point, we sought to separate the influence that the horizontal external force $H$ and the vertical external force $V$ (due to the cable's own weight, $m$ ) had on (28). To achieve this, we analyzed the laying and operation of suspended cables by defining three phases.

Phase I is stressing, in which the external horizontal force, $H$, was applied to the cable. This phase was exclusively influenced by $H$ and the cable acquired its internal tension. Phase II is lifting, in which the external vertical force, $V$, was applied, keeping the force $H$ constant. In this phase, the cable acquired its full curvature and its internal tension hardly changed. This phase was analyzed in detail since it was in this phase when the cable defined its initial profile. The final state of this phase, where the cable was fully raised, corresponded to the initial conditions described in Section 2. Finally, Phase III was operation, which sought to solve (28) using simple arithmetic equations supported by equations and graphical representations obtained during the analysis of the two previous phases. 


\subsection{Phase I: Stressing-Horizontal Static State}

In Phase I, a horizontal load, $H_{1}$, was applied, while the cable was supported along its entire length (Figure 3). The cable was subjected to internal tension, $H_{1}$, and was applied on a cable of length $l / 2$.

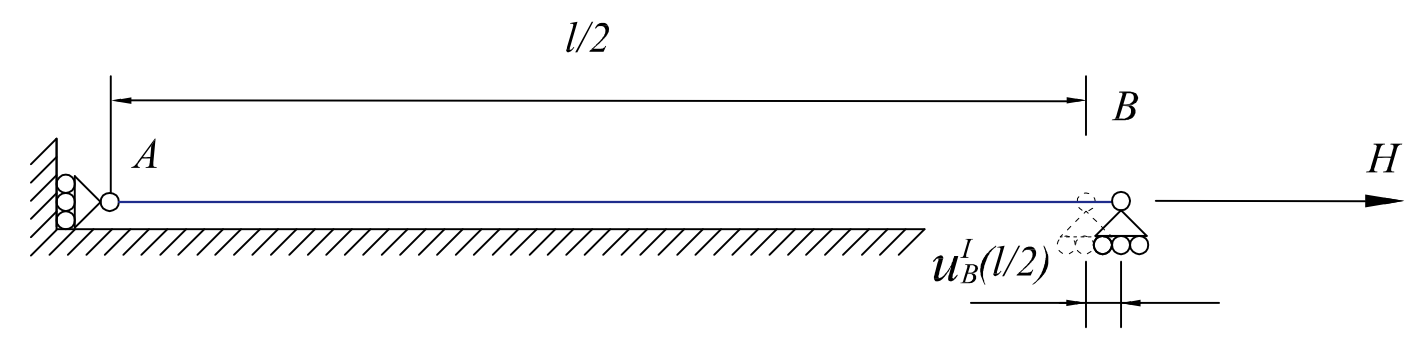

Figure 3. Phase I: Stressing. Horizontal static state. Application of the horizontal external force $H$.

The initial profile of the cable was a horizontal line.

$$
z=0
$$

By applying Hooke's law when the final tension, $H_{1}$, was reached. The horizontal displacement of point $B$ at the end of Phase I can be obtained by

$$
T_{1}=H_{1}, \quad u_{B}^{I}=\int_{0}^{\frac{1}{2}} \varepsilon d x=\int_{0}^{\frac{1}{2}} \frac{H_{1}}{E A} \frac{l}{2}^{2}
$$

where $\varepsilon$ is the strain and the horizontal displacement of point $B$ in Phase $I, u_{B}{ }^{I}$, coincides with the cable length variation. The initial cable length at a temperature $t_{0}$ displaced point $B$. Thus, the final cable length in this phase remains

$$
s_{0}=\frac{l}{2}, \quad u_{B}^{I}=\frac{H_{1}}{E A} \frac{l}{2}, \quad s^{I}=s_{0}+u_{B}^{I}
$$

\subsection{Phase II: Lifting-Curved Static State}

According to Figure 4, only the cable segment of length $s \approx x \operatorname{complied}$ and $V=m g x$ was lifted. When lifting a differential element of the cable, $d s \approx d x$, it rotated an angle $d \theta$, and point $B$ moved a differential element $d \delta$, taking the cable from $b^{\prime}$ (discontinuous line) to $b^{\prime \prime}$ (continuous line). This displacement differential element had a vertical component, $d w$, and a horizontal component, $d u$. During this phase, two segments coexisted in the cable: a straight horizontal segment, $A-a$, and a curved raised segment, $a-b$, which described a parabola, according to (34). 


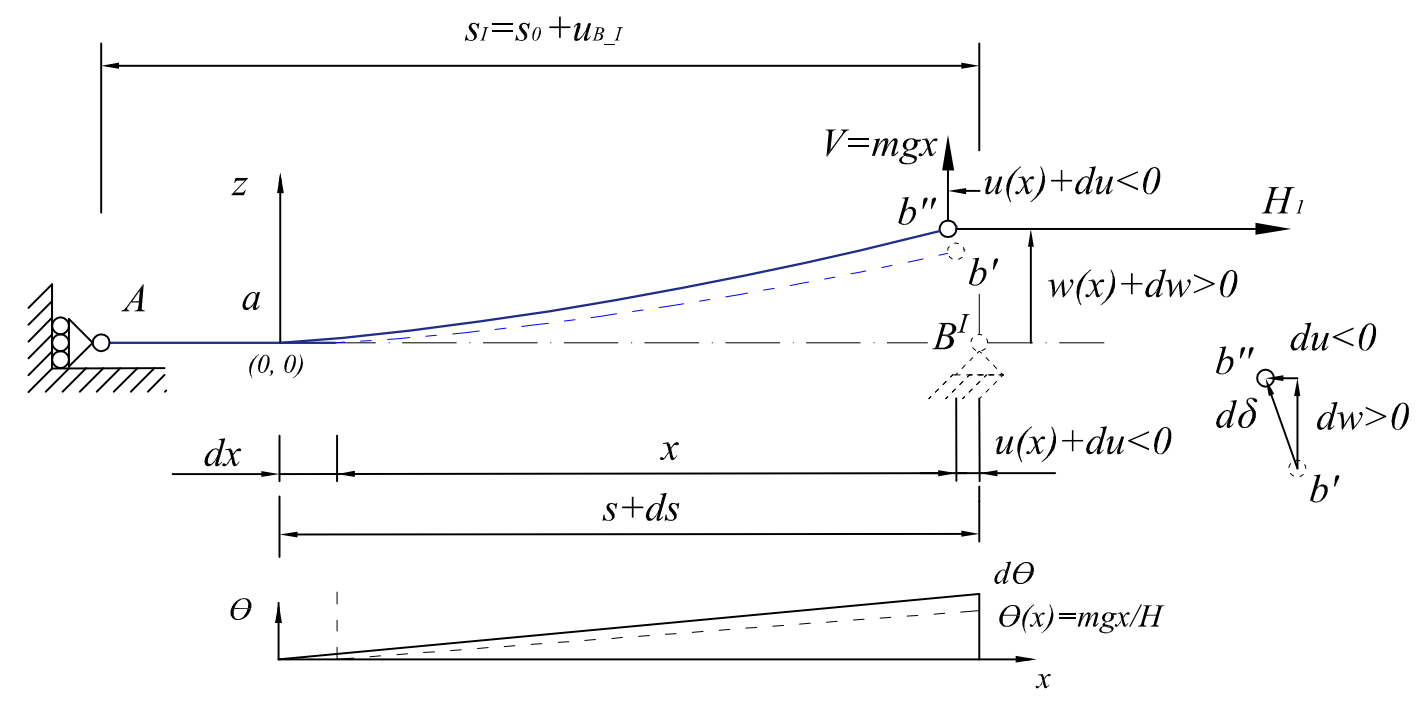

Figure 4. Differential elements in Phase II (lifting). Right segment $A B$ of the final parabola.

\subsubsection{Segment 1: Horizontal Segment-Segment A-a}

As shown in Figure 4, only part of the cable was lifted. The rest remained in the same condition as in Phase $\mathrm{I}$, as well as maintaining the same tension, $T$, since the external force $H_{1}$ remained constant $\left(T=H_{1}\right)$.

\subsubsection{Segment 2: Curved Segment-Segment a-B}

Equations (32)-(34) were obtained by applying the static equilibrium equations, which are easy to apply for high-school students. In this work, the mathematical models developed in Section 2 were applied to the cable shown in Figure 4. The initial profile was a horizontal line, $z=0$, and, in this phase, there was displacement in the $z$ axis, $d w>0$.

$$
d s \approx d x, \quad z=0, \quad d w \neq 0
$$

Replacing (32) in the vertical component of (14) results in

$$
H_{1} \frac{d^{2} w}{d x^{2}}=m_{1} g, \quad \rho_{1}=\frac{H_{1}}{m_{1} g} \rightarrow \frac{d^{2} w}{d x^{2}}=\frac{1}{\rho_{1}}
$$

where $\rho_{1}$ is a good approximation for the radius of curvature of the curve $w$. Integrating (33) results in

$$
w(x)=\frac{m_{1} g x^{2}}{2 H_{1}}=\frac{x^{2}}{2 \rho_{1}} .
$$

The vertical displacement $w$, according to (34), is easily obtained by secondary school students applying the static equations. Calculation difficulties came with horizontal displacement $u$. Next, the horizontal displacement was analyzed in detail to find a simple analytical expression.

The mathematical model for horizontal displacement applied polar coordinates to point $b$.

Cartesian coordinates of point $b$ in Phase II are as follows:

$$
\left(x, w=\frac{x^{2}}{2 \rho_{1}}\right) .
$$


Polar coordinates of point $b$, according to Figure 5 , assume small values for the angle $\theta$, and therefore also for $\varphi$ (Equation (13)).

$$
(\varphi, r) \rightarrow\left\{\begin{array}{c}
\tan \varphi=\frac{w}{x}, \quad \varphi \approx \tan \varphi=\frac{x}{2 \rho} \approx \frac{\theta}{2} \rightarrow w=\varphi x \\
r=\sqrt{x^{2}+z^{2}}=x \sqrt{1+\tan ^{2} \varphi}=\frac{x}{\cos \varphi}
\end{array}\right\} \rightarrow\left(\frac{\theta}{2}, \frac{x}{\cos \varphi}\right)
$$

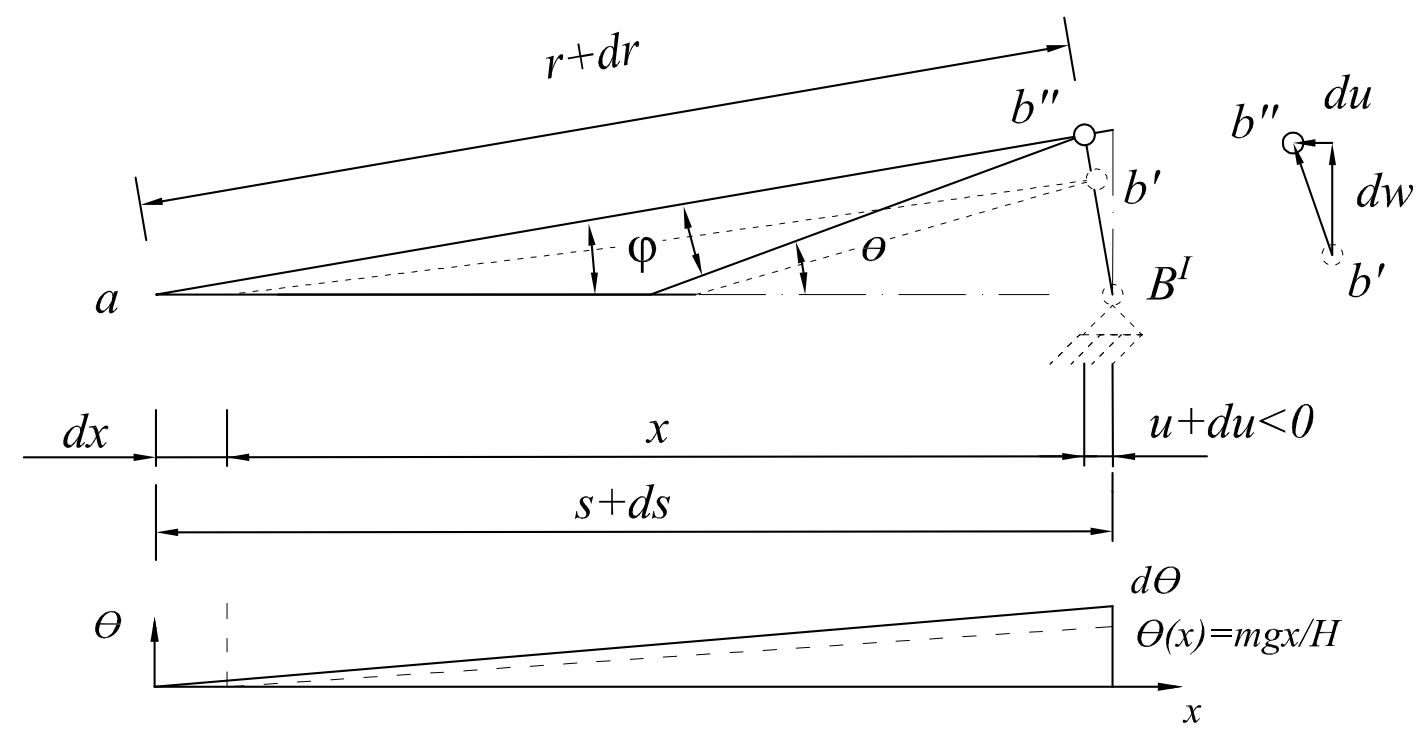

Figure 5. Polar coordinates for the right segment of the parabola, $a-b$ (Phase II). Radius $a B_{I}$.

In Figure 5, when the external force, $V$, was applied at point $B$ (not represented in the figure for simplicity) a differential $d V=m g d s$ increased and a cable element of length $d s$ was raised, which met Equation (37) and was no longer horizontal. Point $a$ was the vertex of the parabola $a-b$ of Equation (34) and moved $d x>0$ to the left. Point $b$ was displaced to the left of $d u$, having negative values, according to the coordinate axes of Figure 5.

$$
s+d s=x+d x-u-d u, \quad x=r \cos \varphi \rightarrow d s=d r \cos \varphi-r \sin \varphi d \varphi-d u
$$

When drawing a circle in the center of $a$, the total length of the cable raised $s+d s$ (segment $a B_{I}$ ). Figure 6 shows that between the polar coordinate $r+d r$ (segment $\left.a b^{\prime \prime}\right)$ and radius $s+d s$, there was a difference $s_{c}+s_{c}$, representation the length applied in defining the cable curvature. Equation (38) was thus satisfied.

$$
s+d s=r+d r+s_{c}+d s_{c} \rightarrow d s=d r+d s_{C}
$$




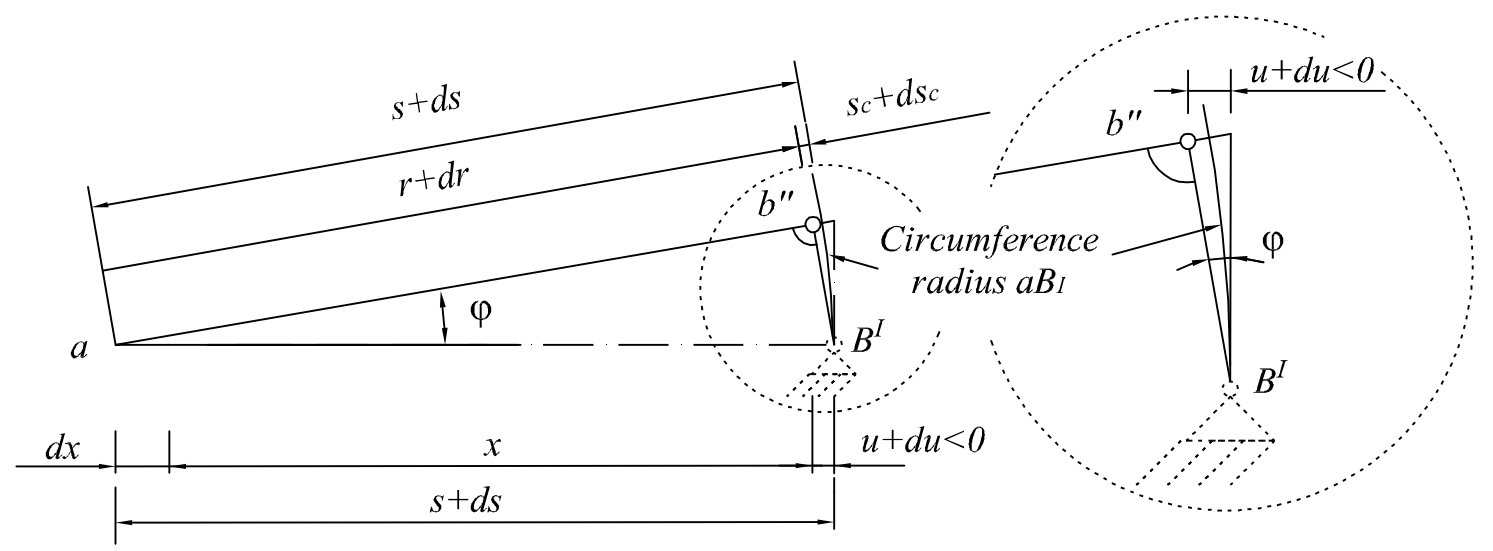

Figure 6. Polar coordinates for the right segment of the parabola $a-b$ (Phase II). Radius $a b^{\prime \prime}$.

Replacing (38) with (37) and approximating for small values of $\varphi$ results in

$$
d r-x \varphi d \varphi-d u=d r+d s_{\mathcal{C}} \rightarrow d u+d s_{\mathcal{c}}=-x \varphi d \varphi .
$$

If it is established as a hypothesis that half of the horizontal displacement of point $b$ is used to follow the profile curvature according to (40), then

$$
d s_{c}=-\frac{d u}{2} .
$$

Therefore, we have obtained an expression for $u(x)$ and $s_{c}(x)$. If $w$ is substituted according to (36), then (39) can be solved as

$$
\begin{aligned}
& u(x)=-\int_{0}^{x} w d \theta \\
& s_{\mathcal{c}}(x)=\int_{0}^{x} w d \varphi .
\end{aligned}
$$

The integral of (41) for $u(x)$ was proportional to the first moment of area for the triangle defined by angle $\theta$, according to Figure 4 . It is referred to as $M$ and was the first-order static moment with respect to the $z$-axis (coordinate origin in the point $a$ ).

$$
\begin{gathered}
u(x)=-\int_{0}^{x} w d \theta=\left\{\begin{array}{c}
w=\frac{x}{2} \theta \\
d \theta=\frac{d x}{\rho}
\end{array}\right\}, \quad u(x)=-\frac{1}{2 \rho} \int_{0}^{x} x \theta d x=-\frac{x^{3}}{6 \rho^{2}} \\
u(x)=-\frac{1}{2 \rho} M, \quad M=\frac{2}{3} x \frac{1}{2} x \frac{x}{\rho} \rightarrow u(x)=-\frac{x^{3}}{6 \rho^{2}}
\end{gathered}
$$

Equation (42) gives an expression for the horizontal displacement of point $B, u$. Therefore, according to the hypothesis of Equation (40), the cable length defines the curvature, $s_{c}$. Both expressions can be obtained by making first-order static moments, which are mathematical tools that students in the final years of secondary education use.

Accepted mathematical models were used to validate the above hypothesis [16].

The mathematical model for horizontal displacement, $u$, was used [16].

We transitioned from an initial horizontal profile, $z=0$, to a curved profile, $w$. The vertical displacements $w(x)$ corresponded to (34). The horizontal component in the straight $(A-a)$ and curved $(a-b)$ segments remained constant and equal to $H_{1}$. Therefore $h=0$, according to (17). If the temperature remains constant at $t_{0}$, it results in the following:

$$
0=\int_{0}^{x_{B}} d u+\frac{1}{2} \int_{0}^{x_{B}}\left(\frac{m g x}{H}\right)^{2} d x
$$


Integrating the horizontal displacement for point $B$ in Phase II results in the following:

$$
u_{B}^{I I}=\frac{m_{1}^{2} g^{2} x^{3}}{6 H_{1}^{2}} \rightarrow u_{B}^{I I}=-\frac{x^{3}}{6 \rho_{1}^{2}} .
$$

The displacement of point $b$ is $w(x)$ in the $z$-axis, according to (34), and $u B_{-} I I(x)$ in the $x$-axis, according to (44). The value of $u_{B_{-} I I}$, according to (44) for a half-span of $l / 2$, corresponds to the length increase of the profile of a parabola with span $l$, according to (8).

Since (44) corresponds to (42), the hypothesis of Equation (40) is correct.

Once the right-hand segment of the cable with a length of $s_{0}=l / 2$ has been raised, the total accumulated horizontal displacement of Phase II and the temperature variation from $t_{0}$ to $t_{1}$ remains as follows:

$$
u_{B}^{T}=\frac{H_{1} l}{2 E A}+\alpha\left(t_{1}-t_{0}\right) \frac{l}{2}-\frac{m_{1}^{2} g^{2} l^{3}}{48 H_{1}^{2}}, \quad w_{B}^{T}=\frac{m_{1} g l^{2}}{8 H_{1}} .
$$

\subsubsection{Segment 2: Curved Segment-Energy Relations}

Energy analysis helps students to understand the meaning of this phenomenon [33]. This section describes the energy relationships that appear in Phases I and II in order to clarify the concepts involved.

The work done by the load is stored in two forms: gravitational potential energy and elastic strain energy of extensions [16]. The external force, $V$, is gradually applied at point $b$, which moves vertically, according to (34), as $V$ increases. The work done for a span, $l$, is

$$
W_{V}=2 \int_{0}^{d} V_{B} d w_{B}=2 \int_{0}^{\frac{l}{2}} \frac{m_{1}^{2} g^{2} x^{2}}{H} d x=\frac{4}{3} V d \rightarrow\left\{\begin{array}{c}
V=m_{1} g \frac{l}{2} \\
d=\frac{m_{1} g l^{2}}{8 H_{1}}
\end{array}\right.
$$

While applying $V$, the external force $H_{1}$ is fully applied. Therefore, it exerts work since point $b$ moves horizontally, according to (44), for a constant temperature, $t_{0}$ :

$$
W_{H_{1}}=2 \int_{0}^{d} H_{1} d u_{B}^{I I}=-2 H_{1} u_{B}^{I I}, \quad u_{B}^{I I}=-\frac{m_{1}^{2} g^{2} l^{3}}{48 H_{1}^{2}} \rightarrow W_{H_{1}}=-\frac{2}{3} V d .
$$

Thus, the total work of the external forces is

$$
W_{T}=W_{V}+W_{H}=-\frac{2}{3} V d .
$$

The gravitational potential energy is given by

$$
V_{g}=2 \int_{0}^{\frac{l}{2}} m_{1} g w d s
$$

Including the constraints given in (32) and substituting (34) into (49), we find that

$$
V_{g}=2 \int_{0}^{\frac{l}{2}} \frac{m_{1}^{2} g^{2} x^{2}}{2 H_{1}} d x=\frac{2}{3} V d
$$

The potential strain energy is depicted as $V_{e}=0$ and conservation of energy requires that

$$
W_{T}=V_{g} .
$$




\subsection{Phase III: Operation-Equation of Static Response}

The cable was tightened, lifted, and fixed at point $B$ for operation (Figure 7).

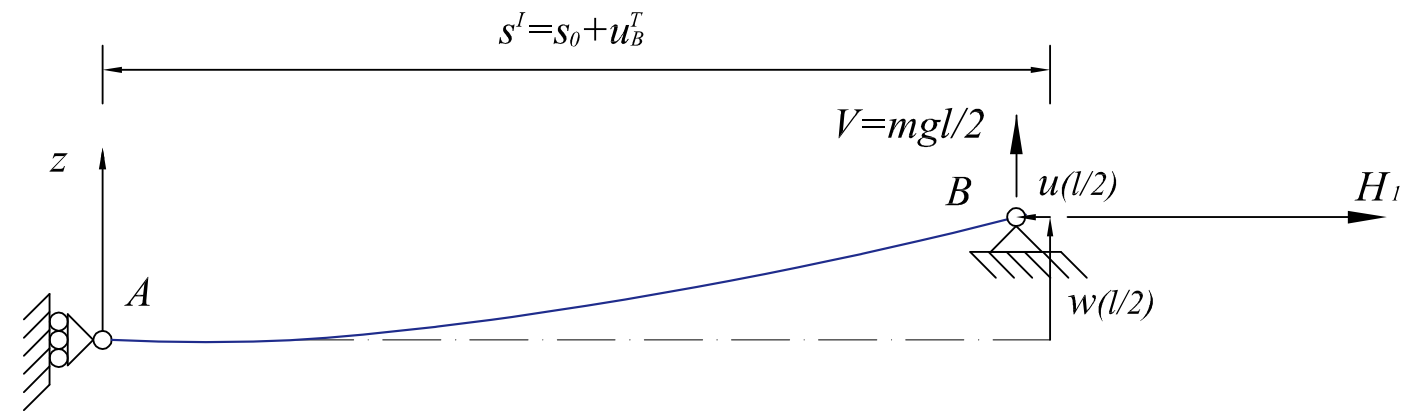

Figure 7. Final static state. Fixed point $B$.

The cable was fixed at point $B$ by changing the static conditions of the vertex of the parabola (point $A$ ) and this it moved in a vertical direction. This was not the case with horizontal displacement, where both points $A$ and $B$ were restricted in their horizontal displacement. Therefore, the horizontal displacements for the same cable under different conditions, 1 and 2, were the same.

$$
\begin{aligned}
& \left.u_{B}^{T}\right|_{2}=\frac{H_{2} l}{2 E A}+\alpha\left(t_{2}-t_{0}\right) \frac{l}{2}-\frac{m_{2}^{2} g^{2} l^{3}}{48 H_{2}^{2}} \\
& \left.u_{B}^{T}\right|_{1}=\frac{H_{1} l}{2 E A}+\alpha\left(t_{1}-t_{0}\right) \frac{l}{2}-\frac{m_{1}^{2} g^{2} l^{3}}{48 H_{1}^{2}}
\end{aligned}
$$

Equation (52) can be obtained by following Phases I, II, and III (for a span of length $l / 2$ ). It is, therefore, identical to (28) (for a span of length $l$ ), which demonstrates the classical cable theory [16,17]. Therefore, we determined that the application of the three phases were valid.

Application of Polar Coordinates at Point B

Once in Phase III, the $x$-coordinate of point $B$ remains constant at $x=+l / 2$. Now, Equation (37) becomes

$$
d s=-d u
$$

Equation (38), using (40), now reads as

$$
d s_{c}=d r=\frac{d s}{2}
$$

Thus, (41) can be written as

$$
d s_{c}=\frac{l}{2} \varphi d \varphi
$$

\subsection{Didactic Procedure for Solving the Equation of Steady-Static Response}

The procedure obtained $\Delta s_{c}$, beginning with a known length variation caused by temperature or stress variations, $\Delta s$, and using (55).

$$
d s_{c}=\frac{l}{2} \varphi d \varphi, \quad \Delta s_{\mathcal{C}}=z_{B} \Delta \varphi
$$

The order in which the variables are grouped in the second member of (55) is significant. When grouped as in (56), the product of the first two variables corresponds to the initial $z$-coordinate of point $B, z_{B 1}$ (see Figure 8 ). 


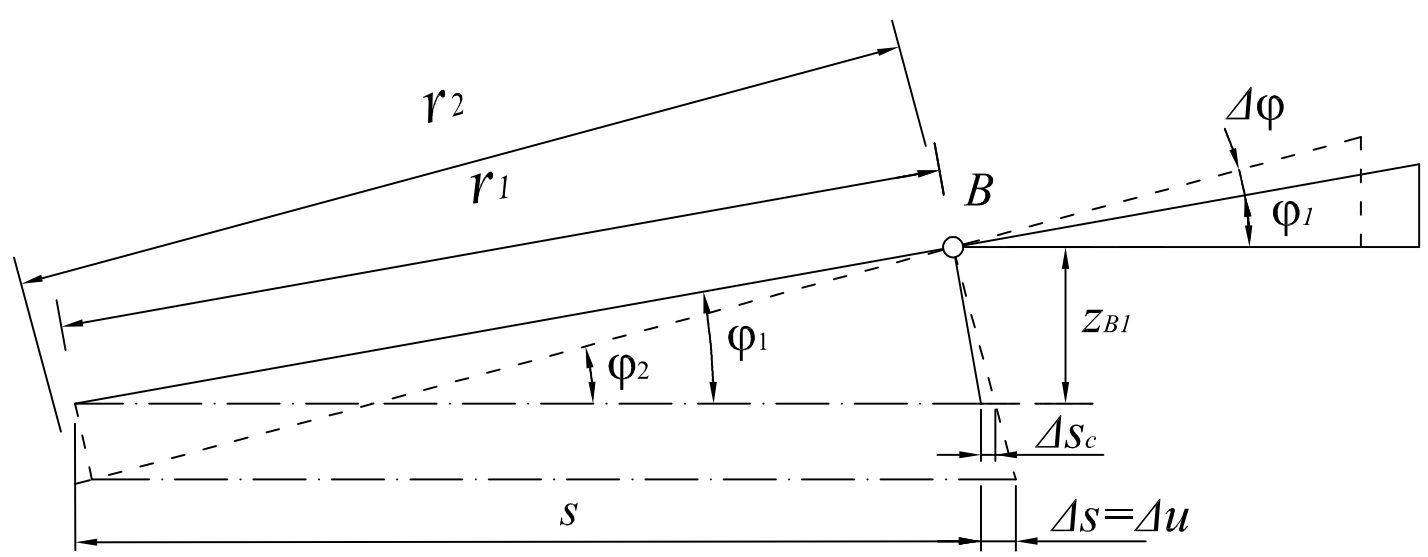

Figure 8. Graphical representation of $\Delta s_{c}$ according to Equation (56).

The calculation procedure starts from initial conditions (subscript 1 ) and obtains a variation of the angle of rotation, $\Delta \theta$, to approximate $H_{2}$ in two steps:

Step 1 uses (56) to determine the length variation caused by temperature changes from $t_{1}$ to $t_{2}, \Delta s$. Then, the previous length is calculated for curvature length, $\Delta s c$. Then, $\Delta \varphi$ and the value of $H_{2}{ }^{I}$ can be obtained as an approximation of $H_{2}$, according to (57).

Step 1:

$$
x=\frac{l}{2}, \quad \varphi_{1}=\frac{m_{1} g x}{2 H_{1}}, \quad z_{B 1}=x \varphi_{1}
$$

$$
\begin{aligned}
& \Delta s_{c}=\frac{\Delta s}{2}, \quad \Delta s=x \alpha\left(t_{2}-t_{1}\right) \\
& \Delta \varphi_{I}=\frac{\Delta s_{c}}{z_{B 1}} \\
& \varphi_{I}=\varphi_{1}+\Delta \varphi_{I} \rightarrow H_{2}^{I}=\frac{m_{2} g x}{2 \varphi_{I}}
\end{aligned}
$$

Step 2 calculates the length variation when changing the cable tension from $H_{1}$ to $H_{2}{ }^{I}, \Delta s$. Then, the previous length is calculated for curvature length, $\Delta s c$. Then, $\Delta \varphi$ and the value of $H_{2}{ }^{I I}$ can be obtained as an approximation of $H_{2}$, according to (58).

Step 2:

$$
x=\frac{l}{2}, \quad \varphi_{1}=\frac{m_{1} g x}{2 H_{1}}, \quad z_{B 1}=x \varphi_{1}, \quad \Delta \varphi_{I}
$$

$$
\begin{aligned}
& \Delta s_{c}=\frac{\Delta s}{2}, \quad \Delta s=\frac{x\left(H_{2}^{I}-H_{1}\right)}{S E} \\
& \Delta \varphi_{I I}=\frac{\Delta \Delta_{c}}{z_{B 1}} \\
& \varphi_{I I}=\varphi_{1}+\Delta \varphi_{I}+\Delta \varphi_{I I} \rightarrow H_{2}^{I I}=\frac{m_{2} g x}{2 \varphi_{I I}} \approx H_{2}
\end{aligned}
$$

\subsection{Application of the Procedure to Cables Used in Low-Voltage Aerial Lines}

The above algorithm was applied to cables for low voltage aerial lines that were referred to in Royal Decree 842/2002, which approved low voltage electrotechnical regulations in Spain [34]. To evaluate the results, the exact values were provided by MATLAB's fsolve algorithm, which uses a variant of an algorithm previously described [35]. It was applied to solve (28).

Table 1 provides the mechanical characteristics of the cable with designation RZ $3 \times 50 \mathrm{Al} / 54.6 \mathrm{Alm}$.

Table 1. Characteristics of cable RZ $3 \times 50$ Al/54.6 Alm.

\begin{tabular}{cc}
\hline Designation & Characteristics \\
\hline$R Z 3 x 50 \mathrm{Al} / 54.5 \mathrm{Alm}$ & $\begin{array}{c}S=54.6 \mathrm{~mm}^{2} ; \quad m=0.755 \mathrm{~kg} \cdot \mathrm{m}^{-1} ; \\
E=6000 \mathrm{~kg} \cdot \mathrm{mm}^{-2} ; \quad \alpha=23 \times 10^{-6}{ }^{\circ} \mathrm{C}^{-1}\end{array}$ \\
\hline
\end{tabular}


The change of static state conditions described in Table 2 was carried out for the cable with designation $R Z 3 x 50 \mathrm{Al} / 54.6 \mathrm{Alm}$, for a span of $l=50 \mathrm{~m}$. The initial state of the conditions corresponded to the maximum tension reached by the cable and the final state corresponded to the maximum sag on the cable. The conditions were obtained according to Spanish standards [34].

Table 2. Conditions for the cable RZ $3 x 50 \mathrm{Al} / 54.6 \mathrm{Alm}$.

\begin{tabular}{ccc}
\hline \multicolumn{2}{c}{ Initial State Conditions: $\boldsymbol{T}_{\text {max }}$} & \multicolumn{2}{c}{ Final State Conditions: $\boldsymbol{d}_{\text {max }}$} \\
\hline$H_{1}=345 \mathrm{kp} ; \quad m_{1}=1.99 \mathrm{~kg} \cdot \mathrm{m}^{-1} ; \quad t_{1}=15^{\circ} \mathrm{C}$ & $H_{2} ;$ & $m_{2}=0.755 \mathrm{~kg} \cdot \mathrm{m}^{-1} ; \quad t_{2}=50^{\circ} \mathrm{C}$ \\
\hline
\end{tabular}

Table 3 shows the solution of each step and the relative error as a percentage of the solution provided by fsolve.

Table 3. Results for the cable RZ $3 \times 50 \mathrm{Al} / 54.6 \mathrm{Alm}$.

\begin{tabular}{cc}
\hline Procedure & Result \\
\hline MATLAB: fsolve & $H_{2}=128.33 \mathrm{kp}$ \\
Step I: & $H_{2}=128.45 \mathrm{kp}$ \\
Error $\%$ & $0.099 \%$ \\
Step II: & $H_{2}=128.02 \mathrm{kp}$ \\
Error $\%$ & $0.063 \%$ \\
\hline
\end{tabular}

Table 4 provides the mechanical characteristics of the cable with designation $R Z 3 \times 95 \mathrm{Al} / 54.6 \mathrm{Alm}$.

Table 4. Characteristics of cable RZ $3 \times 95$ Al/54.6 Alm.

\begin{tabular}{cc}
\hline Designation & Characteristics \\
\hline$R Z 3 x 95 \mathrm{Al} / 54.6 \mathrm{Alm}$ & $S=54.6 \mathrm{~mm}^{2} ; \quad m=1.26 \mathrm{~kg} \cdot \mathrm{m}^{-1} ;$ \\
& $E=6000 \mathrm{~kg} \cdot \mathrm{mm}^{-2} ; \quad \alpha=23 \times 10^{-6}{ }^{\circ} \mathrm{C}^{-1}$ \\
\hline
\end{tabular}

The change of static state conditions described in Table 5 was carried out for the cable with designation $R Z 3 \times 95 \mathrm{Al} / 54.6 \mathrm{Alm}$, for a span of $l=50 \mathrm{~m}$. The initial state of the conditions corresponded to the maximum tension reached by the cable and the final state corresponded to the maximum sag on the cable. The conditions were obtained according to Spanish standards [34].

Table 5. Conditions for the cable RZ $3 x 95 \mathrm{Al} / 54.6 \mathrm{Alm}$.

\begin{tabular}{ccc}
\hline \multicolumn{2}{c}{ Initial state conditions: $\boldsymbol{T}_{\max }$} & \multicolumn{2}{c}{ Final State Conditions: $\boldsymbol{d}_{\text {max }}$} \\
\hline$H_{1}=345 \mathrm{kp} ; \quad m_{1}=2.58 \mathrm{~kg} \cdot \mathrm{m}^{-1} ; \quad t_{1}=15^{\circ} \mathrm{C}$ & $H_{2} ; \quad m_{2}=1.26 \mathrm{~kg} \cdot \mathrm{m}^{-1} ; \quad t_{2}=50^{\circ} \mathrm{C}$ \\
\hline
\end{tabular}

Table 6 shows the solution of each step and the relative error as a percentage of the solution provided by fsolve.

Table 6. Results for the cable RZ $3 x 95$ Al/54.6 Alm.

\begin{tabular}{cc}
\hline Procedure & Result \\
\hline MATLAB: fsolve & $H_{2}=165.017 \mathrm{kp}$ \\
Step I: & $H_{2}=167.67 \mathrm{kp}$ \\
Error $\%$ & $1.00 \%$ \\
Step II: & $H_{2}=166.06 \mathrm{kp}$ \\
Error $\%$ & $0.987 \%$ \\
\hline
\end{tabular}

Table 7 provides the mechanical characteristics of the cable with designation RZ 3x150 Al/80 Alm. 
Table 7. Characteristics of cable RZ 3x150 Al/80 Alm.

\begin{tabular}{cc}
\hline Designation & Characteristics \\
\hline$R Z 3 x 150 \mathrm{Al} / 80 \mathrm{Alm}$ & $S=80 \mathrm{~mm}^{2} ; \quad m=1.78 \mathrm{~kg} \cdot \mathrm{m}^{-1} ;$ \\
& $E=6000 \mathrm{~kg} \cdot \mathrm{mm}^{-2} ; \quad \alpha=23 \times 10^{-6}{ }^{\circ} \mathrm{C}^{-1}$ \\
\hline
\end{tabular}

The change of static state conditions described in Table 8 was carried out for the cable with designation $R Z 3 \times 150 \mathrm{Al} / 80 \mathrm{Alm}$, for a span of $l=50 \mathrm{~m}$. The initial state of the conditions corresponded to the maximum tension reached by the cable and the final state corresponded to the maximum sag on the cable. The conditions were obtained according to Spanish standards [34].

Table 8. Conditions for the cable $R Z 3 \times 150 \mathrm{Al} / 80 \mathrm{Alm}$.

\begin{tabular}{ccc}
\hline \multicolumn{2}{c}{ Initial state conditions: $\boldsymbol{T}_{\max }$} & \multicolumn{2}{c}{ Final state conditions: $\boldsymbol{d}_{\max }$} \\
\hline$H_{1}=444.4 \mathrm{kp} ; \quad m_{1}=3.23 \mathrm{~kg} \cdot \mathrm{m}^{-1} ; \quad t_{1}=15^{\circ} \mathrm{C}$ & $H_{2} ;$ & $m_{2}=1.78 \mathrm{~kg} \cdot \mathrm{m}^{-1} ; \quad t_{2}=50^{\circ} \mathrm{C}$ \\
\hline
\end{tabular}

Table 9 shows the solution of each step and the relative error as a percentage of the solution provided by fsolve.

Table 9. Results for the cable RZ $3 \times 150 \mathrm{Al} / 80 \mathrm{Alm}$.

\begin{tabular}{cc}
\hline Procedure & Result \\
\hline MATLAB: fsolve & $H_{2}=236.77 \mathrm{kp}$ \\
Step I: & $H_{2}=241.69 \mathrm{kp}$ \\
Error $\%$ & $2.079 \%$ \\
Step II: & $H_{2}=240.32 \mathrm{kp}$ \\
Error $\%$ & $2.074 \%$ \\
\hline
\end{tabular}

\section{Discussion}

This work is an example of how intuitive models are useful for students when manually calculating either approximate or exact models in computer simulations.

In this way, affordable mathematical tools provided to students advances learning. Metacognitive knowledge and mathematical intelligence are independent [36]. Metacognitive knowledge can be understood as the ability to recognize the strengths and weaknesses of one's learning process and the subsequent ability to correct them [37], as well as possessing the mathematical intelligence to solve mathematical problems [38].

On the other hand, from secondary education onwards, students must be able to create computer simulations to check the validity of models used in manual calculation. Students are motivated to accept computer simulations [39].

From a didactic point of view, we clarified the process of lifting a suspended cable through defining three phases starting from when the cable extends horizontally to when it is fully raised and fixed at its supports. Equation (52) was obtained by following Phases I, II, and II and is identical to (28), which has been widely obtained with verified models [16,17]. This fact validates the implementation of these phases, yet the practical usefulness of these phases remains to be determined.

It is important to define each summand for (52). The first term corresponded to the increase in length due to Hooke's law; the second corresponded to the increase in length due to temperature; the third corresponded to the increase in cable length to be added to the straight line $r_{a b}$ that defined the profile of the cable, $s_{c}$ (see Figures 5 and 6). The negative sign of this third summand corresponded to the fact that point $b$, when bending the cable in Phase II, moved to the left (negative direction, Equation (36)).

Equation (41) was obtained by analyzing Phase II in polar coordinates, which also corresponded to the second summation in the second member of Equation (8), representing the parabola's arc 
length. The latter is of great importance for the mathematical procedure in suspended cables and is traditionally obtained via integral calculation. This is a difficulty for students in secondary education, since they often have not yet studied integral calculus or it is not contemplated in their curricula. Equation (44) was obtained as the first-order static moment of the triangular area defined by angle $\theta$ (see Figure 5 and Equation (42)). This fact is of notable didactic importance at the secondary education level, since students have knowledge of mathematics applied to the calculation of static moments and centers of gravity. Thus, (42) provides a calculation tool for students that allows them to advance their studies.

Energy helps students understand the meaning of this phenomenon [33]. For this reason, it has been considered useful to obtain energy relations in Phases I and II, in order to clarify the concepts involved in these phases. They are simple expressions that can be used to perform didactic problems while teaching, although obtaining them requires integral calculus. Applying energetic relationships allows one to clarify the physical processes that occurs during each phase. Thus, during Phase I of stressing, only elastic potential energy is accumulated, while during Phase II of lifting, the cable accumulates gravitational potential energy and elastic potential energy, the latter being negligible.

Equations (37)-(39) are of considerable importance when developing the calculation procedure described in Section 3.4. The polar coordinate $r$ is related to the cable length $s$ and to the Cartesian coordinate $x$, according to Figure 5 and Equation (38). In (39), (41) was replaced by (37) after differentiation, wherein the approximation for small values of the angle $\theta$ was made. It is important to point out that if, in (37), the approximation for small angles was made first, the information provided by the differential process would be lost. In that case, Equation (39), fundamental to the calculation procedure, would be reduced to a trivial equality $(0=0)$. This fact has great didactic value since it recognizes the implications of the approaches made in the model. These details stimulate the interest of many students. Examples of systems with similar effects on students are the elastic pendulum [40] or the three-body problem [41]. These are simple approaches that can present complex or simple dynamic behaviors depending on their state.

In (39), the calculation process was stopped because two unknowns appeared, $s_{\mathcal{C}}$ and $u$. A hypothesis is still needed, which is stated in (40). This is a conceptual advance for the didactic development of suspended cables. It states that only half of the horizontal displacement of point $\mathrm{b}$ during Phase II is applied when varying the cable curvature and therefore the angle $\theta$ at point $B$ (see Figure 6). Solutions for (39) and (40) results in (41). It provides an expression for both $s_{c}$ and $u$ in Phase II. In the case of $u$, it is identical to the expression of Equation (44) from widely validated mathematical models [16,17]. This validates the hypothesis of $(40)$, which is half of the horizontal displacement $u$ (in modulus) in Phases II and III. This is responsible for the curvature of the cable profile.

Considering the importance of (41), it is convenient to indicate that the expression obtained corresponds to first-order static moments of triangular figures (see (42)). This fact favors their study in secondary education and specifically for students not required to have skills in differential calculus.

For the calculation procedure of cable conditions changes in Phase III, Figure 8 is relevant. It graphically shows the result of (56), interpreted as the product of a radius by an angle. This graphic tool has great didactic power since it allows the visualization of a calculation procedure, as well as locates the main magnitudes involved in $\Delta s, \Delta u$, and $\Delta s_{c}$. Even the veracity of the hypothesis of Equation (40) can be assessed. This affords students the possibility to understand mathematical models through formulas (i.e., Equation (56)) and graphs (i.e., Figure 8).

In Section 3, the calculation procedure was applied to the three most used cables in low-voltage aerial lines. The cables were laid in a span of $l=50 \mathrm{~m}$, which is an average span for this type of line. A change in static conditions was applied from conditions, implying maximum internal tension in the cable (subscript 1) to conditions implying maximum sag in the cable (subscript 2). Step I corresponded to the variation in curvature due to temperature (i.e., Equation (57)), achieving good results in all three cases with results having errors below $2.1 \%$ with respect to the exact solution provided by MATLAB's 
fsolve. The calculation procedure described in Section 3.4 can be reduced to step I, especially when concerning temperature variation. The application of step II slightly improved the results.

Since these were standard problems in low-voltage aerial line design, they became puzzle problems [10]. These were complete problems with statements, analytical resolution procedures supported by graphics, and concrete/intuitive analytical solutions. However, this was an approximate solution because the procedure did not lead to an exact solution, as it is not an algorithm. The procedure allows students to advance their studies by having mathematical tools that analyze cables in any condition. These are tools that students are familiar and friendly with. The problems were posed to students in secondary education, specifically in vocational education and training in the electrical branch. They accepted the calculation procedure positively because it allowed them to manually make a complete problem. They can thus obtain a computer solution to compare results. In addition, students can be encouraged to search independently for other methods of solving the equation of steady-static response in suspended cables, such as the Cardano's formulae or the Ruffini's rule.

In future works, the described calculation procedure should be applied to more complex calculation conditions, i.e., cables with several spans and different lengths [20], and spans with supports at different levels. The main point of interest is to apply the procedure to cables with large thermal uprating, which would increase their power transfer capacity [42-44]. The conductors (i.e., high-temperature and low-sag conductors) can support temperatures up to $150{ }^{\circ} \mathrm{C}$, against $80^{\circ} \mathrm{C}$ of the conductors they replace [45]. In this case, there were large temperature variations and this was where the calculation procedure described in this paper obtained the best results.

\section{Conclusions}

In this study, an approximate method to calculate low voltage aerial lines was successfully developed. The method facilitated the acquisition of professional and mathematic competences for vocational education and training students in the electrical branch. Educational exercises were herein proposed and students provided affordable calculations and analysis tools.

Three phases have been differentiated in the laying and operation of the suspended cables, owing to which a graphic procedure has been obtained in which each of the magnitudes involved in the process are identified. It is an approximate but useful tool for solving exercises manually, and for the student to have a simple model of resolution and understanding of the physical phenomena involved.

The equation of steady-static response in suspended cables to solve is a cubic equation, which can be solved by well-known methods such as the Cardano's formulae or the Ruffini's rule, among others. This work provides a graphical solution of the equation of steady-static response and requires applying the physical laws used in suspended cables. Step I of the procedure considers the variation in cable length with the change in temperature, and step II evaluates the variation in length with the change in tension. This procedure has great didactic value, since it allows the student to apply previously acquired concepts, which are necessary for the study of suspended cables.

As disadvantages or limitations of the proposed procedure, it provides only approximate results to the exact solution and requires more time to resolve the exercise. In addition, it is a specific procedure, not applicable to other subjects of the course.

Author Contributions: Conceptualization, J.A.-R., Á.-J.C.-F., J.L.-M., and M.G.-G.; methodology, J.A.-R., Á.-J.C.-F., J.L.-M., and M.G.-G.; software, J.A.-R., Á.-J.C.-F., J.L.-M., and M.G.-G.; validation, J.A.-R., Á.-J.C.-F., J.L.-M., and M.G.-G.; formal analysis, J.A.-R., Á.-J.C.-F., J.L.-M., and M.G.-G.; investigation, J.A.-R., Á.-J.C.-F., J.L.-M., and M.G.-G.; resources, J.A.-R., Á.-J.C.-F., J.L.-M., and M.G.-G.; data curation, J.A.-R., Á.-J.C.-F., J.L.-M., and M.G.-G.; writing-original draft preparation, J.A.-R., Á.-J.C.-F., J.L.-M., and M.G.-G.; writing-review and editing, J.A.-R., Á.-J.C.-F., J.L.-M., and M.G.-G.; visualization, J.A.-R., Á.-J.C.-F., J.L.-M., and M.G.-G.; supervision, J.A.-R., Á.-J.C.-F., J.L.-M., and M.G.-G.; and project administration, J.A.-R., Á.-J.C.-F., J.L.-M., and M.G.-G. All authors have read and agreed to the published version of the manuscript.

Funding: This research received no external funding. 
Acknowledgments: José Agüero-Rubio wants to thank the Consejería de Educación de la Junta de Andalucía for the research stay during the 2011-12 academic year. Further, he would like to thank the vocational education and training students in the branch of electricity of the IES Alhamilla in Almeria (Spain) for their positive predisposition to realize the examples presented in this work.

Conflicts of Interest: The authors declare no conflict of interest.

\section{References}

1. Real Decreto 1127/2010 de 10 de Septiembre. [Royal Decree 1127/2010 of 10 of September]; The Title of Superior Technician in Electrotechnical and Automated Systems Is Established and Their Minimum Teachings Are Established. Ed. Boletín Oficial del Estado de 8 de octubre de 2010 [Official State Gazette of October 8]. In BOE (Boletín Oficial del Estado); State Agency Official State Gazette: Madrid, Spain, 2010; Number 244; p. 85006.

2. UNESCO Institute for Statistics. International Standard Classification of Education: ISCED 2011; UIS: Montreal, QC, USA, 2012. [CrossRef]

3. Boyse, C.O.; Simpson, N.G. The problem of conductor sagging on overhead transmission lines. J. Inst. Electr. Eng. Part II Power Eng. 1944, 91, 219-238.

4. Landau, M. Incremental method for sag-tension calculations. Trans. Am. Inst. Electr. Eng. 1951, 70, $1564-1571$. [CrossRef]

5. Lummis, J.; Fischer, J.R. Practical design of transmission line tensions. Electr. Eng. 1955, 74, 39. [CrossRef]

6. Balangó, D.; Mémeth, B.; Göcsei, G. Predicting conductor sag of power lines in a new model of Dynamic Line Rating. In Proceedings of the IEEE Electrical Insulation Conference (EIC), Seattle, WA, USA, 7-10 June 2015.

7. Dong, X. Analytic method to calculate and characterize the sag and tension of overhead lines. IEEE Trans. Power Deliv. 2016, 31, 20646-20671.

8. Huilier, D.G.E. Forty Years' Experience in Teaching Fluid Mechanics at Strasbourg University. Fluids 2019, 4, 199. [CrossRef]

9. Moreno-Clemente, J. Evolución del cálculo mecánico de conductores en líneas aéreas con la aplicación de la informática. DYNA 2001, 76, 6-10.

10. Leite, L.; Dourado, L. Laboratory activities, science education and problem-solving skills. Procedia Soc. Behav. Sci. 2013, 106, 1677-1686. [CrossRef]

11. Garrett, R.M. Issues in science education: Problem-solving, creativity and originality. Int. J. Sci. Educ. 1987, 85, 113-119. [CrossRef]

12. Roberts, R. Using different types of practical within a problem-solving model of science. Sch. Sci. Rev. 2004, 9125-9137.

13. Dodge, R.E.; Fisher, B.E.; King, J.J.; Kuehl, P.G.; Matsuki, S.; Mitchell, W.E.; Dailey, J.F.; Boyajian, D.M. Introducing the Structural Engineering Encounter laboratory: A physical approach to teaching statics, mechanics of materials and structural analysis. World Trans. Eng. Technol. Educ. 2011, 9, 86-91.

14. Teik-Cheng, L. Revisiting the elasticity solution for a simply supported beam under sinusoidal load. Int. J. Mech. Eng. Educ. 2018, 46, 41-49.

15. Raviv, D.; Barb, D. A Visual, Intuitive and Engaging Approach to Explaining the Center of Gravity Concept in Statics. In Proceedings of the 2019 126th ASEE Annual Conference \& Exposition, Tampa, FL, USA, 15-19 June 2019.

16. Irvine, H.M. Statics of a Suspended Cable. In Cable Structures; The MIT Press: Cambridge, NJ, USA, 1981; pp. $43-44$.

17. Treyssède, F. Free linear vibrations of cables under thermal stress. J. Sound Vib. 2009, 327, 1-8. [CrossRef]

18. Yaobing, Z.; Chaohui, H.; Lincong, C.; Peng, J. Nonlinear vibration behaviors of suspended cables under two-frequency excitation with temperature effects. J. Sound Vib. 2018, 416, 279-294.

19. Majid, K.; Masoud, F.; László, E.K. Estimation of stresses in atmospheric ice during Aeolian vibration of power transmission lines. J. Wind Eng. Ind. Aerodyn. 2010, 98, 592-599.

20. Wu, C.; Yan, B.; Zhang, L.; Zhang, B.; Li, Q. A method to calculate jump height of iced transmission lines after ice-shedding. Cold Reg. Sci. Technol. 2016, 125, 40-47. [CrossRef]

21. Bertand, C.; Plut, C.; Ture Savadkoohi, A.; Lamarque, C.H. On the modal response of mobile cables. Eng. Struct. 2020, 210, 110231. [CrossRef] 
22. Wang, L.; Rega, G. Modelling and transient planar dynamics of suspended cables with moving mass. Int. J. Solids Struct. 2010, 47, 2733-2744. [CrossRef]

23. Gattulli, V.; Martinelli, L.; Perotti, F.; Vestroni, F. Nonlinear oscillations of cables under harmonic loading using analytical and finite element models. Comput. Methods Appl. Mech. Eng. 2004, 193, 68-85. [CrossRef]

24. Luongo, A.; Rega, G.; Vestroni, F. Monofrequent oscillations of a non-linear model of a suspended cable. J. Sound Vib. 1982, 82, 247-259. [CrossRef]

25. Rega, G.; Vestroni, F.; Benedettini, F. Parametric analysis of large amplitude free vibrations of a suspended cable. Int. J. Solids Struct. 1984, 20, 95-105. [CrossRef]

26. Lianhua, W.; Jianjun, M.; Jian, P.; Lifeng, L. Large amplitude vibration and parametric instability of inextensional beams on the elastic foundation. Int. J. Mech. Sci. 2013, 67, 1-9.

27. Rezaiee-Pajand, M.; Mokhtari, M.; Massodi, A.R. A novel cable element for nonlinear thermo-elastic analysis. Eng. Struct. 2018, 167, 431-444. [CrossRef]

28. Pereira da Silva, A.A.; de Barros Bezerra, J.M. A Model for Uprating Transmission Lines by Using HTLS Conductors. IEEE Trans. Power Deliv. 2011, 26, 2180-2188.

29. Yang, Y.B.; Tsay, J.Y. Geometric nonlinear analysis of cable structures with a two node cable element by generalized displacement control method. Int. J. Struct. Stab. Dyn. 2007, 7, 571-588. [CrossRef]

30. Luongo, A.; Zulli, D. Statics of Shallow Inclined Elastic Cables under General Vertical Loads: A Perturbation Approach. Mathematics 2018, 6, 24. [CrossRef]

31. Rychlewski, J. On Hooke's law. J. Appl. Math. Mech. 1984, 48, 303-314. [CrossRef]

32. Lepidi, M.; Gattulli, V. Static and dynamic response of elastic suspended cables with thermal effects. Int. J. Solids Struct. 2012, 49, 1103-1116. [CrossRef]

33. Nordine, J.; Fortus, D.; Lehavi, Y.; Neumann, K.; Krajcik, J. Modelling energy transfers between systems to support energy knowledge in use. Stud. Sci. Educ. 2018, 54, 177-206. [CrossRef]

34. Royal Decree 842/2002 of 2 of August. Low Voltage Electro-Technical Regulations and Their Complementary Technical Instructions; Ministerio de Ciencia y Tecnología: Madrid, Spain, 2002.

35. Powell, M.J.D. A Fortran Subroutine for Solving Systems of Nonlinear Algebraic Equations. Numerical Methods for Nonlinear Algebraic Equations; Atomic Energy Research Establishment: Harwell, UK, 1968.

36. Chytry, V.; Říčan, J.; Eisenmann, P.; Medová, J. Metacognitive knowledge and mathematical intelligence-two significant factors influencing school performance. Mathematics 2020, 8, 969. [CrossRef]

37. Azevedo, R. Theoretical, conceptual, methodological, and instructional issues in research on metacognition. Metacognition Learn. 2009, 4, 87-95. [CrossRef]

38. Eisenmann, P.; Novotná, J.; P`ribyl, J.; B`rehovský, J. The development of a culture of problem solving with secondary students through heuristic strategies. Math. Ed. Res. J. 2015, 27, 535-562. [CrossRef]

39. Rodríguez-Martín, M.; Rodríguez-Gonzálvez, P.; Sánchez-Patrocinio, A.; Ramón-Sánchez, J. Short CFD Simulation Activities in the Context of Fluid-Mechanical Learning in a Multidisciplinary Student Body. Appl. Sci. 2019, 9, 4809. [CrossRef]

40. Cuerno, R.; Rañada, F.; Ruiz-Lorenzo, J.J. Deterministic chaos in the elastic pendulum: A simple laboratory for nonlinear dynamics. Am. J. Phys. 1992, 60, 73-79. [CrossRef]

41. Hayes, W. Computer simulations, exact trajectories, and the gravitational N-body problem. Am. J. Phys. 2004, 72, 1251-1257. [CrossRef]

42. Daconti, J.R.; Lawry, D.C. Increasing power transfer capability of existing transmission lines. IEEE Xplore 2003. [CrossRef]

43. Albizu, I.; Mazón, A.J.; Valverde, V.; Buigues, G. Aspects to take into account in the application of mechanical calculation to high-temperature low-sag conductors. IET Gener. Transm. Dis. 2010, 4, 631-640. [CrossRef]

44. Mazón, A.J.; Zamora, I.; Eguía, P.; Torres, E.; Miguélez, S.; Median, R.; Saenz, J.R. Gap-type conductors: Influence of high temperature in the compression clamp systems. In Proceedings of the 2003 IEEE Bologna Power Tech Conference, Bolgna, Italy, 23-26 June 2003.

45. Michiori, A.; Nguyen, H.-M.; Alessandrini, S.; Bremnes, J.B.; Dierer, S.; Ferrero, E.; Nygaard, B.-E.; Pinson, P.; Thomaidis, N. Forecasting for dynamic line rating. Renew. Sust. Energ. Rev. 2015, 52, 1713-1730. [CrossRef] 